\title{
Association between older age and outcome after cardiac surgery: a population-based cohort study
}

\author{
Wei Wang ${ }^{1}$, Sean M Bagshaw ${ }^{1,2,5^{*}}$, Colleen M Norris ${ }^{1,3,4}$, Rami Zibdawi ${ }^{3}$, Mohamad Zibdawi ${ }^{1,2}$ and \\ Roderick MacArthur ${ }^{1}$, for the APPROACH Investigators
}

\begin{abstract}
Objective: Octogenarians (aged $\geq 80$ years) are increasingly being referred for cardiac surgery. We aimed to describe the morbidity, mortality, and health services utilization of octogenarians undergoing elective cardiac surgery.

Methods: Retrospective population-based cohort study of adult patients receiving elective cardiac surgery between January 12004 and December 31 2009. Primary exposure was age $\geq 80$ years. Outcomes were 30-day, 1- and 5-year mortality, post-operative complications, and ICU/hospital lengths of stay. Multi-variable logistic and Cox regression analyses were used to explore the association between older age and outcome.

Results: Of 6,843 patients receiving cardiac surgery, 544 (7.9\%) were octogenarians. There was an increasing trend in the proportion of octogenarians undergoing surgery during the study period $(0.3 \%$ per year, $\mathrm{P}=0.073)$. Octogenarians were more likely to have combined procedures (valve plus coronary artery bypass or multiple valves) compared with younger strata $(p<0.001)$. Crude 30-day, 1-year and 5-year mortality for octogenarians were 3.7\%, 10.8\% and 29.0\%, respectively. Compared to younger strata, octogenarians had higher adjusted 30-day (OR 4.83, 95\%Cl 1.30-17.92; $\mathrm{P}=0.018)$ and 1-year mortality (OR 4.92; $95 \% \mathrm{Cl}, 2.32-10.46 . \mathrm{P}<0.001)$. Post-operative complications were more likely among octogenarians. Octogenarians had longer post-operative stays in ICU and hospital, and higher rates of ICU readmission ( $P<0.001$ for all). After multi-variable adjustment, age $\geqq 80$ years was an independent predictor of death at 30-days and 1 year.

Conclusions: Octogenarians are increasingly referred for elective cardiac surgery with more combined procedures. Compared to younger patients, octogenarians have a higher risk of post-operative complications, consume greater resources, and have worse but acceptable short and long-term survival.
\end{abstract}

Keywords: Octogenarian, Cardiac Surgery, Complication, Mortality

\section{Background}

Population aging is a global phenomenon with significant implications for health care systems in the developed world. In 2012, over 5.2 million people in Canada were aged over 65 years, representing $14.9 \%$ of total population. Of these, approximately 1.4 million $(4.2 \%$ of total population) were octogenarians (aged $\geq 80$ years) [1]. Associated with this increasingly older population, the demand for surgery, in particular cardiac surgery, is expected to markedly increase $[2,3]$.

\footnotetext{
* Correspondence: bagshaw@ualberta.ca

${ }^{1}$ Division of Cardiac Surgery, Mazankowski Alberta Heart Institute, University of Alberta, Edmonton, Alberta, Canada

${ }^{2}$ Division of Critical Care Medicine, Faculty of Medicine and Dentistry,

University of Alberta, Edmonton, Alberta, Canada

Full list of author information is available at the end of the article
}

Prior studies evaluating the course and outcomes of older patient receiving cardiac surgery have notable limitations, including being relatively small, only investigating certain type or types of cardiac procedures, failing to include adjusted analyses of outcomes relative to younger age strata, and reporting only on short-term outcomes [4-7].

We hypothesized that octogenarians undergoing cardiac surgery would have higher perioperative mortality and complication rates and consume greater health resources. Our objectives were to describe the population-based short-term and long-term mortality, major morbidity, and health services utilization in patients aged $\geq 80$ years undergoing elective cardiac surgery. 


\section{Methods}

The study was approved by the Health Research Ethics Board at the University of Alberta prior to commencement. The requirement for written consent was waived.

\section{Study design, setting, population}

This was a retrospective population-based cohort study performed at the Mazankowski Alberta Heart Institute (MAHI), University of Alberta (Edmonton, Canada) between January 12004 and December 31 2009. The MAHI is the only referral center for adult cardiac surgery in northern Alberta. There are nine adult cardiac surgeons at the MAHI performing approximately 11001200 adult open cardiac surgery procedures annually (excluding heart transplant, lung transplant, and mechanical assist device implantation).

All adult patients receiving elective cardiac surgery were potentially eligible. We excluded those patients receiving heart and lung transplantation, emergent cardiac surgery, mechanical assist device implantation and those aged less than 18 years. Octogenarians were defined by an age $\geq 80$ years according to their age on the day of surgery. For the purpose of analyses, the entire cohort was categorized into four age strata: 18-49 years, 50-64 years, 65-79 and $\geq 80$ years, respectively.

\section{Study protocol}

Patients were identified by interrogation of the Alberta Provincial Project for Outcome Assessment in Coronary Heart Disease (APPROACH)) registry. The APPROACH registry prospectively captures detailed clinical information on adult patients with known or suspected coronary artery disease (CAD) investigated in the province of Alberta (more information can be found at http://www. approach.org/). Patients entered into the registry are longitudinally followed after cardiac catheterization for all cardiac-specific investigations, interventions (i.e. percutaneous coronary intervention [PCI] or coronary artery bypass grafting surgery $[\mathrm{CABG}]$ ) and outcomes. Data elements in the registry include socio-demographic features (i.e. age, sex), cardiovascular risk factors and co-morbidities (i.e. hypertension, dyslipidemia, stroke, congestive heart failure (CHF), chronic pulmonary disease, end stage kidney disease (ESKD) on dialysis, peripheral vascular disease (PVD), diabetes mellitus, liver and gastrointestinal disease, malignancy), coronary anatomy as defined by the Duke Index [8], left ventricular ejection fraction (EF), prior thrombolytic therapy, prior myocardial infarction (MI), prior CABG surgery, and prior angioplasty. In addition, the registry also captures several peri-operative variables specific for cardiac surgery (i.e. procedure type, cardiopulmonary bypass and aortic cross clamp time, use of intra-operative balloon pump $[\mathrm{IABP}])$ and surgery specific complications and outcomes. Quarterly merges of the APPROACH registry with the Bureau of Vital Statistics was used for ascertainment of vital status.

\section{Operational definitions}

Post-operative major bleeding was defined as blood loss from chest tubes greater than $400 \mathrm{ml} \times 1 \mathrm{hr}$ or $300 \mathrm{ml} \times$ $2 \mathrm{hrs}$ or $200 \mathrm{ml} \times 3 \mathrm{hrs}$. Surgical wound infection was defined as purulent discharge from sternal wounds and/or positive culture results from blood, urine, sputum/lungs and incisions. Cardiac arrest was defined as a recorded cardiac arrest or pulseless electric arrest (PEA) in the post-operative period that required cardiopulmonary resuscitation. Heart block was defined as second degree type 2 or third degree heart block occurring beyond post-operative day 3. Pulmonary complication was defined as post-operative ventilation time greater than 48 hours or need for re-intubation. Neurologic complication was defined as post-operative transient ischemic attack (TIA), stroke or seizure. Acute kidney injury (AKI) was defined as an increase of $\geq 50 \%$ in serum creatinine $(\mathrm{Cr})$ from pre-operative baseline value, or post-operative urine output $<0.5 \mathrm{ml} / \mathrm{kg} / \mathrm{hr} \times 12$ hours.

\section{Statistical analysis}

The primary exposure of interest across all analyses was octogenarians (i.e. age $\geq 80$ years). The outcomes were 30-day, 1-year and 5-year mortality, post-operative complications (i.e. bleeding, infection, neurologic events, pulmonary complications, AKI, atrial fibrillation, cardiac arrest, heart block) and health service utilization (ICU stay, hospital stay and ICU re-admission). Continuous data were reported as means \pm standard deviations (SD) and were compared by Student's t-test and analysis of variance (ANOVA) where appropriate. Categorical data were reported as proportions and compared using $\mathrm{X}^{2}$ test or Fisher's exact test where appropriate. Multivariate logistic regression analysis was used to identify independent risk factors for 30-day and 1-year mortality in all patients with age strata. Initial covariates considered included sex, preoperative co-morbid illnesses, procedure type, CPB and/or aortic cross clamp time, and post-operative complications. Data were presented as adjusted odds ratios (ORs) with 95\% confidence intervals (CIs). Kaplan-Meier survival curve was used for survival analysis. Cox regression analysis was used to explore the association of long-term mortality across age strata while controlling for potential confounding covariates. The associations were reported as hazard ratios (HR) with $95 \%$ CIs. A p-value of $<0.05$ was considered statistically significant for all comparisons. All analysis was performed by using IBM SSPS software.

\section{Results}

Of 7,302 patients receiving cardiac surgery during the study, $23(0.3 \%)$ were excluded due to age <18 years; $384(5.3 \%)$ 

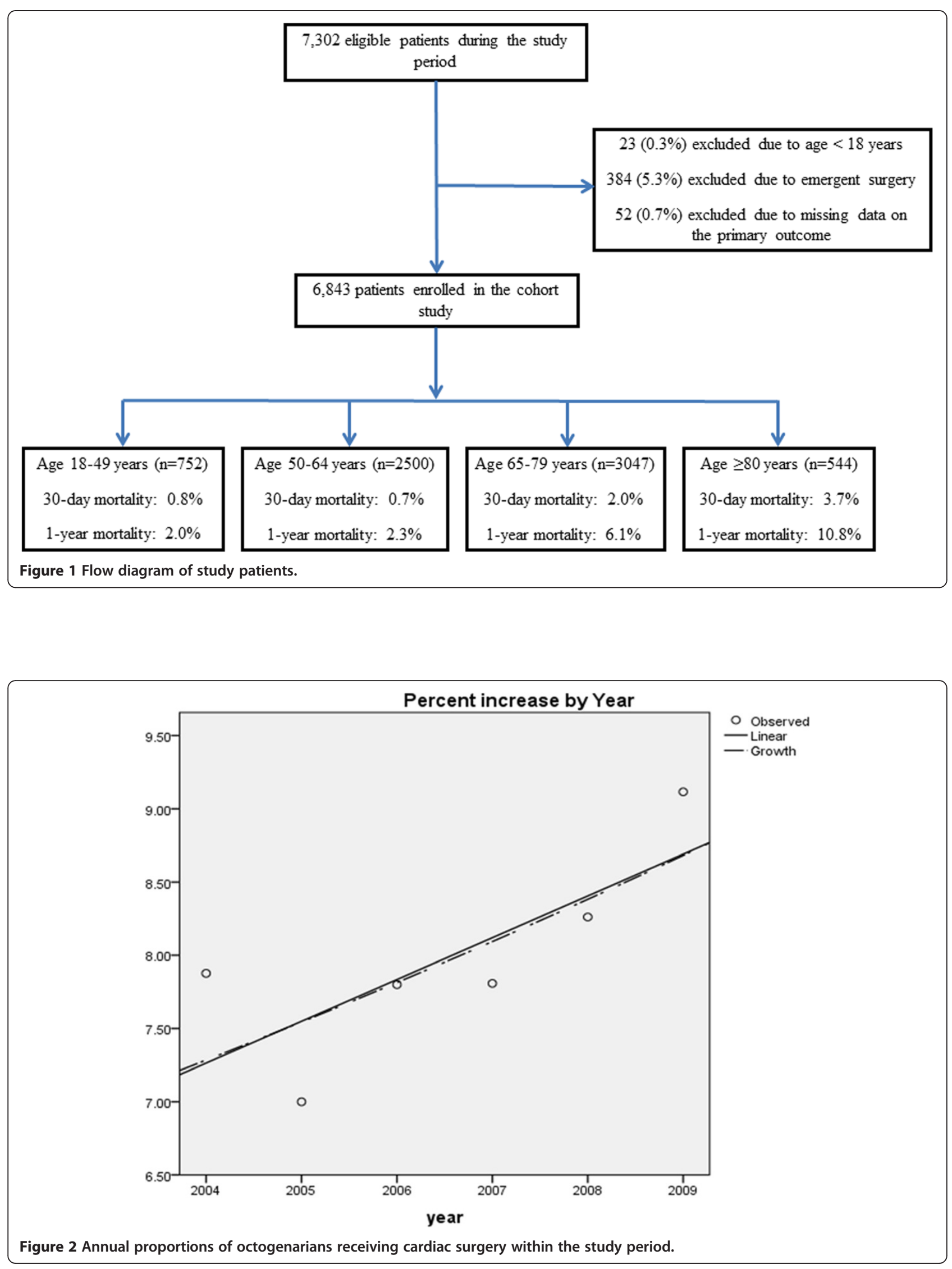
excluded due to emergent surgery, and $52(0.7 \%)$ excluded due to missing data on the primary outcome. (Figure 1) The final cohort comprised of 6,843 patients undergoing elective cardiac surgery. Of these, 752 (11.0\%) were aged between 18 to 49 years; 2,500 (36.5\%) between 50 to 64 years; 3,047 (44.5\%) between 65 to 79 years and 544 (7.9\%) were aged $\geq 80$ years. The median (range) age of those $\geq 80$ years was 82.5 years $(80.0-92.1)$, with $19.1 \%(\mathrm{n}=104) \geq 85$ years and $1.3 \%(\mathrm{n}=7) \geq 90$ years, respectively. Linear regression showed a trend for a greater proportion of patients aged $\geq 80$ years receiving cardiac surgery during the study period (estimated relative annual increase 3\%; $\mathrm{P}=0.073$ ) (Figure 2).

\section{Baseline characteristics}

Octogenarians had higher prevalence of hypertension, prior MI, CHF, stroke, and malignancy when compared with younger strata (Table 1). Octogenarians had lower prevalence of ESKD and had lower BMI values when compared with younger groups. Octogenarians were also less likely to be undergoing re-operation.

\section{Surgery type}

Octogenarians were more likely to undergo combined cardiac procedures, in particular aortic value replacement and coronary artery bypass, when compared with younger strata. This was associated with comparatively longer durations of CPB and aortic cross-clamp (Table 1).

\section{Mortality}

Crude 30-day, 1-year and 5-year mortality for octogenarians were $3.7 \%, 10.8 \%$ and $29.0 \%$, respectively. The OR of adjusted 30-day and 1-year mortality in octogenarians

Table 1 Pre-operative characteristics and type of surgery across the four age strata

\begin{tabular}{|c|c|c|c|c|c|}
\hline Variables & Age $18-49(n=752)$ & Age $50-64(n=2500)$ & Age 65-79 $(n=3047)$ & Age $\geq 80(n=544)$ & $P$ value \\
\hline Age (year) & $40.6 \pm 8.9$ & $58.5 \pm 4.1$ & $72.4 \pm 4.3$ & $83.1 \pm 2.4$ & $<0.001$ \\
\hline Male (\%) & $71.5 \%$ & $80.9 \%$ & $74.7 \%$ & $73.0 \%$ & $<0.001$ \\
\hline Hypertension (\%) & $42.9 \%$ & $77.6 \%$ & $84.3 \%$ & $86.0 \%$ & $<0.001$ \\
\hline Hyperlipidemia (\%) & $64.5 \%$ & $94.9 \%$ & $94.0 \%$ & $90.9 \%$ & $<0.001$ \\
\hline Diabetes (\%) & $14.9 \%$ & $33.8 \%$ & $34.0 \%$ & $26.1 \%$ & $<0.001$ \\
\hline Previous MI (\%) & $32.3 \%$ & $50.7 \%$ & $51.7 \%$ & $53.8 \%$ & $<0.001$ \\
\hline CHF (\%) & $12.0 \%$ & $11.7 \%$ & $17.8 \%$ & $24.5 \%$ & $<0.001$ \\
\hline PVD (\%) & $2.7 \%$ & $6.7 \%$ & $11.6 \%$ & $11.8 \%$ & $<0.001$ \\
\hline Stroke (\%) & $7.0 \%$ & $8.9 \%$ & $16.3 \%$ & $21.8 \%$ & $<0.001$ \\
\hline CRF on dialysis (\%) & $2.4 \%$ & $1.3 \%$ & $1.5 \%$ & $0.4 \%$ & 0.028 \\
\hline Malignancy (\%) & $1.3 \%$ & $2.0 \%$ & $5.6 \%$ & $7.2 \%$ & $<0.001$ \\
\hline BMl & $29.4 \pm 5.8$ & $30.1 \pm 5.9$ & $28.8 \pm 5.1$ & $26.8 \pm 4.5$ & $<0.001$ \\
\hline Re-operation (\%) & $21.5 \%$ & $6.4 \%$ & $6.9 \%$ & $4.5 \%$ & $<0.001$ \\
\hline Re-op adult congenital (\%) & $10.2 \%$ & $0.3 \%$ & $0.1 \%$ & $0.0 \%$ & $<0.001$ \\
\hline Pre-op Cr ( $\mu \mathrm{mol} / \mathrm{L})$ & $108.1 \pm 107.1$ & $103.1 \pm 79.0$ & $112.1 \pm 83.7$ & $109.3 \pm 39.5$ & 0.04 \\
\hline \multicolumn{6}{|l|}{ Type of Surgery } \\
\hline CABG & $42.0 \%$ & $73.2 \%$ & $67.8 \%$ & $52.4 \%$ & $<0.001$ \\
\hline AVR & $16.0 \%$ & $5.0 \%$ & $4.4 \%$ & $3.9 \%$ & $<0.001$ \\
\hline MVR & $15.6 \%$ & $5.8 \%$ & $5.3 \%$ & $4.4 \%$ & $<0.001$ \\
\hline Combined surgery & $9.8 \%$ & $12.6 \%$ & $21.2 \%$ & $36.3 \%$ & $<0.001$ \\
\hline$A V R+C A B G$ & $1.2 \%$ & $4.6 \%$ & $11.1 \%$ & $24.3 \%$ & $<0.001$ \\
\hline $\mathrm{MVR}+\mathrm{CABG}$ & $1.3 \%$ & $4.1 \%$ & $5.5 \%$ & $5.0 \%$ & $<0.001$ \\
\hline 2 or more valves & $7.3 \%$ & $3.9 \%$ & $4.6 \%$ & $7.0 \%$ & $<0.001$ \\
\hline PVR/TVR & $10.6 \%$ & $1.0 \%$ & $0.5 \%$ & $0.0 \%$ & $<0.001$ \\
\hline Others & $6.0 \%$ & $2.3 \%$ & $0.8 \%$ & $1.3 \%$ & $<0.001$ \\
\hline CPB time (min) & $123.0 \pm 62.1$ & $115.9 \pm 52.4$ & $123.9 \pm 55.2$ & $129.6 \pm 55.3$ & $<0.001$ \\
\hline Cross Clamp time (min) & $79.1 \pm 54.9$ & $78.7 \pm 44.3$ & $85.8 \pm 47.9$ & $92.0 \pm 48.4$ & $<0.001$ \\
\hline off-pump surgery & $9.6 \%$ & $1.3 \%$ & $0.9 \%$ & $0.4 \%$ & $<0.001$ \\
\hline
\end{tabular}

MI: myocardial infarct; CHF: congestive heart failure; PVD: peripheral vascular disease; ESKD: end stage kidney disease; BMI: body mass index; Cr: creatinine, EF: ejection fraction; CABG: coronary artery bypass grafting; AVR: aortic valve repair/replacement; MVR: mitral valve repair/replacement; PVR: pulmonary valve repair/ replacement; TVR: tricuspid valve repair/replacement; CPB: cardiopulmonary bypass. 
were 4.83 (95\% CI $1.30-17.92, \mathrm{P}=0.018$ ) and 4.92 (95\%CI 2.32-10.46, $\mathrm{P}<0.001$ ), respectively (referent group $18-49$ years).

\section{Post-operative complications}

Octogenarians had significant higher risk for all major post-operative complications (bleeding, infection, neurologic events, pulmonary complications, AKI, atrial fibrillation, cardiac arrest, heart block). Octogenarians also had higher utilization of post-operative continuous renal replacement therapy (CRRT) and a trend for higher utilization of peri-operative IABP (Table 2).

\section{Health service utilization}

Octogenarians had longer durations of stay in ICU and hospital (Table 2). Octogenarians were also considerably more likely to require ICU readmission. The crude 30-day, 1-year and 5-year mortality in octogenarians who had cardiovascular surgical ICU (CVICU) re-admission were $10.2 \%, 40.8 \%$ and $59.2 \%$. The likelihood of not being discharged home or to a skilled nursing facility was higher for octogenarians (Table 2).

Factors associated with 30-day, 1-year and 5-year mortality In multi-variable analysis, age $\geq 80$ years was independently associated with increased risk of death at 30 days (adjusted OR 4.83, 95\% CI 1.30-17.92, P = 0.0018) and at 1 -year (adjusted OR 4.92, 95\% CI 2.32-10.46, P <0.001) (Tables 3 and 4).

Age $\geq 80$ years was the strongest independent factor affecting long-term survival (hazard ratio [HR] 5.30,
95\% CI 3.70-7.59, $\mathrm{P}<0.001$ ) (Table 5; Figure 3). While procedure type was not independently associated with short or mid-term mortality; those receiving combined procedures had worse long term survival.

\section{Discussion}

We performed a large population-based cohort study evaluating the incidence, clinical course, outcomes and health utilization of octogenarians undergoing elective cardiac surgery.

\section{Key findings}

Our study had several notable findings. Firstly, the proportion of octogenarians receiving cardiac surgery appears to be increasing. Secondly, octogenarians had significantly higher short and long-term mortality compared with younger patients after adjustment for relevant confounders. Thirdly, octogenarians were more likely to require combined procedures, resulting in longer exposure to cardiopulmonary bypass. Moreover, despite octogenarians having fewer selected comorbid diseases (i.e. ESKD) or undergoing re-operation, the rate of post-operative complications, including ICU readmission, was considerably higher when compared with younger age strata. Finally, octogenarians had markedly longer durations of stay in ICU and hospital and were far less likely to return home after surgery.

\section{Strengths and limitations}

There are important limitations to our study. Firstly, our cohort was assembled from a single center's experience

Table 2 Post-operative complications and health service utilization

\begin{tabular}{|c|c|c|c|c|c|}
\hline Variables & Age $18-49(n=752)$ & Age $50-64(n=2500)$ & Age $65-79(n=3047)$ & Age $\geq 80(n=544)$ & $P$ value \\
\hline Bleeding (re-exploration) & $2.0 \%$ & $1.4 \%$ & $2.3 \%$ & $2.8 \%$ & 0.04 \\
\hline Infection & $6.2 \%$ & $7.4 \%$ & $11.4 \%$ & $13.4 \%$ & $<0.001$ \\
\hline Neurologic events & $1.3 \%$ & $1.3 \%$ & $3.7 \%$ & $7.4 \%$ & $<0.001$ \\
\hline Pulmonary complications & $14.1 \%$ & $12.7 \%$ & $20.5 \%$ & $30.3 \%$ & $<0.001$ \\
\hline AKI & $6.5 \%$ & $4.7 \%$ & $11.2 \%$ & $16.2 \%$ & $<0.001$ \\
\hline Atrial fibrillation & $15.1 \%$ & $28.0 \%$ & $41.1 \%$ & $45.8 \%$ & $<0.001$ \\
\hline Cardiac arrest & $1.5 \%$ & $1.8 \%$ & $3.4 \%$ & $5.5 \%$ & $<0.001$ \\
\hline Heart block & $2.7 \%$ & $1.8 \%$ & $2.9 \%$ & $5.0 \%$ & $<0.001$ \\
\hline $\mathrm{ABBP}$ & $3.0 \%$ & $3.1 \%$ & $3.9 \%$ & $4.2 \%$ & 0.27 \\
\hline CRRT & $2.7 \%$ & $1.7 \%$ & $4.1 \%$ & $6.4 \%$ & $<0.001$ \\
\hline CVICU LOS (hr) & $87.5 \pm 385.6$ & $67.7 \pm 145.0$ & $107.7 \pm 248.7$ & $158.8 \pm 343.6$ & $<0.001$ \\
\hline Hospital LOS & $8.7 \pm 14.4$ & $8.1 \pm 14.7$ & $11.3 \pm 17.7$ & $15.8 \pm 24.2$ & $<0.001$ \\
\hline CVICU re-admission & $3.9 \%$ & $2.6 \%$ & $4.6 \%$ & $9.0 \%$ & $<0.001$ \\
\hline \multicolumn{6}{|l|}{ Discharge location } \\
\hline Home & $92.1 \%$ & $90.6 \%$ & $77.1 \%$ & $56.1 \%$ & $<0.001$ \\
\hline Other facilities & $7.9 \%$ & $9.4 \%$ & $22.9 \%$ & $43.9 \%$ & $<0.001$ \\
\hline
\end{tabular}

AKI: acute kidney injury; IABP: intra-aortic balloon pump; CRRT: continuous renal replacement therapy; LOS: length of stay. 
Table 3 Significant independent predictive variables for 30-day mortality by multivariate logistic regression analysis

\begin{tabular}{lll}
\hline Factors & OR $(\mathbf{9 5 \%}$ Cl) & P value \\
\hline Pre-operative factors & & \\
Male sex & $3.00(1.75-5.15)$ & $<0.001$ \\
Age $\geq 80$ (referent group 18-49 years) & $4.83(1.30-17.92)$ & 0.018 \\
ESKD on dialysis & $6.54(2.52-16.94)$ & $<0.001$ \\
EF 35-50\% (referent group EF > 50\%) & $2.29(1.08-4.86)$ & 0.032 \\
EF $<35 \%$ (referent group EF > 50\%) & $4.07(1.70-9.74)$ & 0.002 \\
Intra-operative factors & & \\
CPB time & $1.01(1.01-1.02)$ & $<0.001$ \\
Post-operative complications & & \\
Pulmonary complications & $2.39(1.30-4.41)$ & 0.005 \\
Cardiac arrest & $20.20(10.64-38.34)$ & $<0.001$ \\
Acute kidney injury on CRRT & $5.13(2.57-10.21)$ & $<0.001$
\end{tabular}

OR: odds ratio; Cl: confidence interval; CRF: chronic renal failure; EF: ejection fraction; CPB: cardiopulmonary bypass; CRRT: continuous renal replacement therapy.

in Canada, was retrospective, and considered only patients referred for elective surgery. This may limit the generalizability of our study and we recognize the process of selection of octogenarians for elective surgery may be variable within and across institutions and jurisdictions. However, our study utilizes a large catchment from a

Table 4 Significant independent predictive variables for 1-year mortality by multivariate logistic regression analysis

\begin{tabular}{lll}
\hline Factors & OR (95\% Cl) & P value \\
\hline Pre-operative factors & & \\
Age 65-79 (referent group 18-49 years) & $3.01(1.52-5.98)$ & 0.002 \\
Age $\geq 80$ (referent group 18-49 years) & $4.92(2.32-10.46)$ & $<0.001$ \\
CHF & $2.13(1.54-2.94)$ & $<0.001$ \\
Peripheral vascular disease & $2.04(1.40-2.96)$ & $<0.001$ \\
ESKD on dialysis & $6.80(3.68-12.55)$ & $<0.001$ \\
EF <35\% (referent group EF $>50 \%)$ & $1.83(1.12-3.01)$ & 0.017 \\
Intra-operative factors & & \\
CPB time & $1.01(1.00-1.01)$ & 0.001 \\
Post-operative complications & & \\
Neurologic events & $1.82(1.13-2.93)$ & 0.014 \\
Pulmonary complications & $2.14(1.53-3.00)$ & $<0.001$ \\
Cardiac arrest & $5.38(3.36-8.62)$ & $<0.001$ \\
CVICU re-admission & $1.61(1.04-2.48)$ & 0.034 \\
Acute kidney injury on CRRT & $6.27(4.03-9.75)$ & $<0.001$ \\
\hline
\end{tabular}

OR: odds ratio; $\mathrm{Cl}$ : confidence interval; CHF: congestive heart failure; CRF: chronic renal failure; EF: ejection fraction; CPB: cardiopulmonary bypass; CRRT: continuous renal replacement therapy; CVICU: cardiovascular surgical intensive care unit.
Table 5 Significant risk factors for long-term survival by Cox regression analysis

\begin{tabular}{lll}
\hline Factors & HR (95\% Cl) & P value \\
\hline Age 65-79 (referent group 18-49 years) & $2.81(2.02-3.90)$ & $<0.001$ \\
Age $\geq 80$ (referent group 18-49 years) & $5.30(3.70-7.59)$ & $<0.001$ \\
Pre-operative co-morbidities & & \\
Type 1 Diabetes & $1.98(1.17-3.34)$ & 0.011 \\
Type 2 Diabetes & $1.43(1.25-1.64)$ & $<0.001$ \\
Smoking & $1.52(1.25-1.86)$ & $<0.001$ \\
CHF & $1.72(1.47-2.00)$ & $<0.001$ \\
PVD & $1.47(1.24-1.74)$ & $<0.001$ \\
Stroke & $1.33(1.14-1.56)$ & $<0.001$ \\
ESKD on dialysis & $3.61(2.64-4.94)$ & $<0.001$ \\
Malignancy & $2.08(1.66-2.61)$ & $<0.001$ \\
EF 35-50\% (referent group EF $>50 \%)$ & $1.20(1.00-1.43)$ & 0.045 \\
EF <35\% (referent group EF $>50 \%)$ & $1.54(1.23-1.94)$ & $<0.001$ \\
Surgery type & & \\
AVR + CABG (referent group isolated CABG) & $1.61(1.29-2.00)$ & $<0.001$ \\
MVR + CABG (referent group isolated CABG) & $1.31(1.00-1.70)$ & 0.047 \\
2 or more valves (referent group isolated CABG) & $1.48(1.08-2.04)$ & 0.015 \\
Post-operative complications & & \\
Infection & $1.28(1.07-1.53)$ & 0.007 \\
Neurologic events & $1.45(1.12-1.88)$ & 0.004 \\
Pulmonary complications & $1.27(1.08-1.50)$ & 0.004 \\
Acute kidney injury on CRRT & $2.10(1.74-2.54)$ & $<0.001$ \\
Cardiac arrest & $2.72(2.07-3.58)$ & $<0.001$ \\
CVICU re-admission & $1.32(1.05-1.67)$ & 0.019 \\
\hline
\end{tabular}

HR: hazard ratio; Cl: confidence interval; PCl: percutaneous coronary intervention; CHF: congestive heart failure; PVD: peripheral vascular disease CVA: cerebral vascular attack; CRF: chronic renal failure; EF: ejection fraction CABG: coronary artery bypass grafting; AVR: aortic valve repair/replacement MVR: mitral valve repair/replacement; CRRT: continuous renal replacement therapy; CVICU: cardiovascular surgical intensive care unit.

relatively isolated geographical region of Canada, our cohort was relatively large with complete ascertainment of long-term vital status, and we utilized the high fidelity data prospectively captured with the APPROACH database. Secondly, while we were able to capture hospital discharge disposition and long-term vital status, we were unable to describe quality-adjusted survival or perform more formal cost analyses associated with elective cardiac surgery in octogenarians.

\section{Interpretation and context with prior literature}

Owing to the demographic change worldwide, the relative proportion of older persons is increasing. Data from Australia and New Zealand demonstrated a 5.6\% annual increase of octogenarians admitted to ICU [9]. It is not surprising that elderly patients are more commonly 


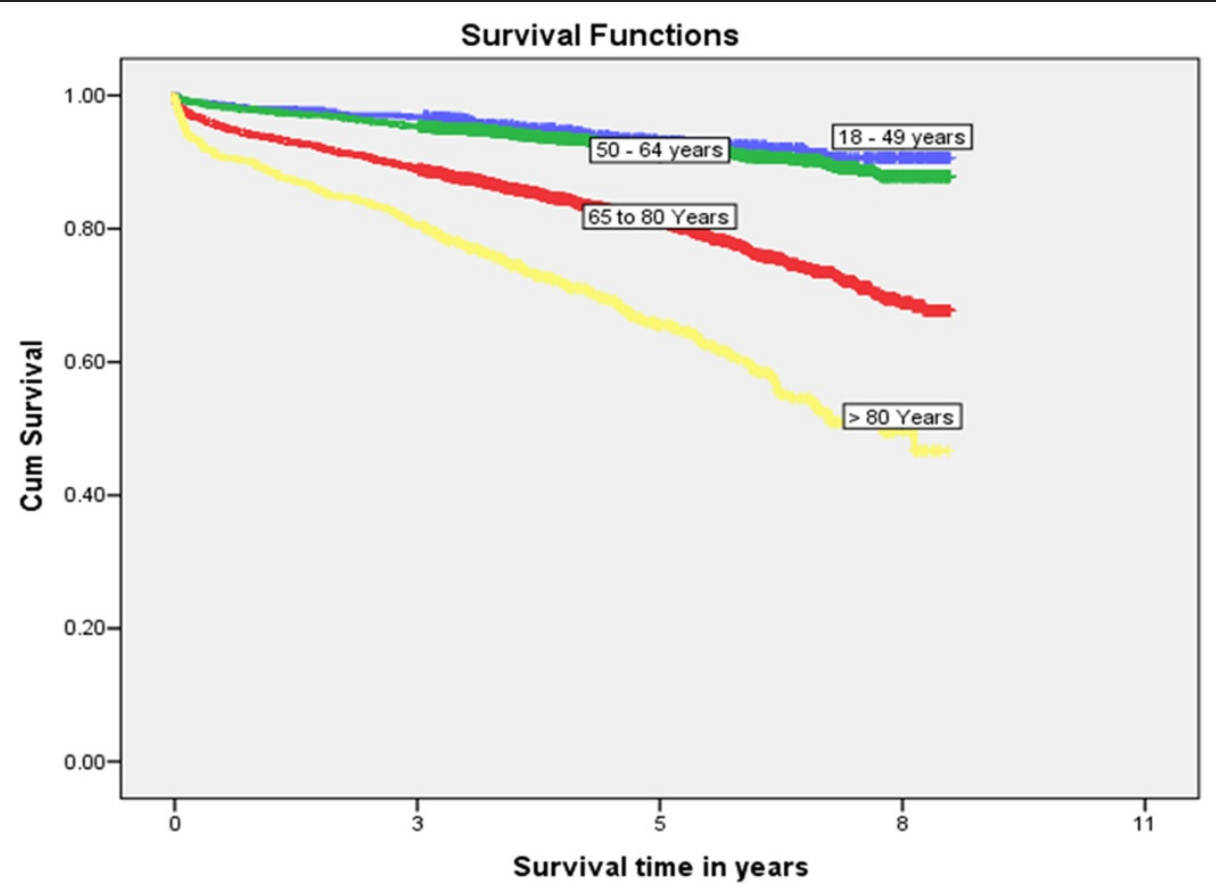

Figure 3 Kaplan-Meier survival curve for long-term survival.

referred to cardiac surgery. In fact, the average age for patients undergoing isolated CABG has increased from 55.8 (1990) to 68.6 year (2007) in Germany [10]. In large observational studies, Bhamidipati et al. and Alexander et al. reported $6.7-7.0 \%$ of all patients undergoing cardiac surgeries were aged $\geq 80$ years. In our study cohort, the rate of octogenarians was modestly higher at $7.9 \%$. Precise estimates of the numbers of octogenarians receiving cardiac surgery and their course are vital for resource planning, as our study has clearly shown these patients have longer more complicated post-operative stays that consumer greater resources that will likely impact cardiac surgical capacity and throughput. Although there was no previous data demonstrating the trend of octogenarians undergoing cardiac surgery, our study showed a small but steady annual increase in the number of octogenarians receiving surgery. As aging is a global phenomenon involved both developed and developing countries, we believe this trend of increasing numbers of octogenarians undergoing cardiac surgery would be evidenced by all high volume cardiac surgery centres in the near future.

As a consequence of older patient referral for cardiac surgery, cardiac pathology is often more considerable. Indeed, we found $36.3 \%$ of octogenarians received combined cardiac procedures (predominantly AVR and CABG), which is among the highest rates compared to previous studies [10-12] and associated with longer CPB and aortic cross clamp time. It is not surprising that octogenarians with more complex procedures have higher risk for major post-operative complications and consequently greater health service utilization (i.e. longer hospital stay, higher ICU re-admission and greater utilization of organ support) and overall costs. Cox regression analysis also suggested combined surgery was associated with worse long term survival. This will present a challenge for cardiac surgical programs to maintain capacity and accommodate the growing demand of this demographic coupled with their higher resource utilization. It is likely that improved and transparent mechanisms for risk assessment and prioritization are needed.

One concern with increasing numbers of octogenarians undergoing more combined cardiac surgery is the high operational mortality. Operating on this specific demographic is not only a challenge to cardiac surgeons but also a challenge to cardiologists, anesthesiologists, CVICU intensivists, and the whole medical system [11]. Previous studies have shown that the in-hospital mortality in octogenarians undergoing isolated CABG, AVR and MVR were $6.8 \%-14.3 \%$ [5,12-14], 4.5\%-12.6\% [6,15-17], and $2.7 \%-18.5 \%$ [7,18], respectively. In a multi-center retrospective study gathering data from 22 high volume cardiac centers in the United States, the reported in-hospital mortality rates for octogenarians after cardiac surgery were $8.1 \%$ for isolated CABG, $10.1 \%$ for combined CABG and AVR, and $19.6 \%$ for combined CABG and MVR [19]. In our study, despite more combined cardiac procedures and longer $\mathrm{CPB} /$ cross clamp time, the crude 30 -day mortality was only $3.7 \%$, and the 1-year and 5-year mortality were $10.8 \%$ and $29.0 \%$ among octogenarians, respectively. Although still 
significantly higher than patients of younger age groups, the short-term and long-term survival in octogenarians are better than previous studies. Indeed, the 29.0\% 5year mortality in octogenarians (mean age 83.1 years) undergoing cardiac surgery is lower than the 5 -year estimated mortality of an average Canadian at age of 83 years ( $40.5 \%$ in male and $30.4 \%$ in female) [20]. These observations confirm that informed selection of older patients for cardiac surgery can translate into acceptable post-operative survival.

Post-operative complications are a source of major morbidity and a driver of health resource use. Across the entire spectrum of complications, the rates are markedly higher among octogenarians [21]. While some occur commonly in the post-operative period, many translate into need for increased intensity of support, downstream morbidity and disability. Indeed, post-operative complications contribute to higher ICU readmission rates and longer durations of ICU and hospital stay. For those octogenarians requiring ICU readmission, in hospital death was $35 \%$ and only $41 \%$ were discharged home. In addition, postoperative complications were independently associated with 30-day and 1-year mortality.

In our opinion, thoughtful patient selection is necessary to optimize post-operative outcomes, in particular in older patients. The vulnerability to less favorable outcomes after cardiac surgery may not be age-specific, but rather reflect "physiologic age". Pre-operative risk assessment may need to consider the emerging concept of frailty as a modifying factor for post-operative course and outcome. Observational data have shown in patients undergoing cardiac surgery that frailty is an independent risk factor for post-operative complications, mortality and institutionalization, after adjusting for age [22]. In our study, we found that in addition to age $\geq 80$ years, pre-operative low EF and pre-operative dialysis dependence were also significant independent risk factors predictive of 30-day mortality. These may be important additional variables to consider when constructing novel clinical risk assessment tools unique to older frail patients referred for surgery, as well as informed decision-making about undergoing surgery and appropriate resource planning.

\section{Conclusions}

The number of octogenarians referred for cardiac surgery is increasing. Age $\geq 80$ years was associated with higher risk of post-operative complications and short and long-term mortality. Octogenarians also have greater post-operative health service utilization. While clinical outcomes may be acceptable with careful patient selection, these data should be utilized to better inform discussions about prognosis, recovery and ultimate resource planning.
Competing interests

The authors declare that they have no competing interests.

\section{Authors' contributions}

WW: Study design, data collecting and manuscript writing. SMB: Study design, statistical analysis and interpretation, and manuscript writing. CMN: Statistical analysis and interpretation. RZ: Data collecting. MZ: Study design and data collecting. RM: Study design and manuscript writing. All authors read and approved the final manuscript.

\section{Acknowledgements}

This study was unfunded.

Dr. Bagshaw holds a Canada Research Chair in Critical Care Nephrology and is a Clinical Investigator supported by Alberta Innovates - Health Solutions (Al-HS).

\section{Author details}

${ }^{1}$ Division of Cardiac Surgery, Mazankowski Alberta Heart Institute, University of Alberta, Edmonton, Alberta, Canada. ${ }^{2}$ Division of Critical Care Medicine, Faculty of Medicine and Dentistry, University of Alberta, Edmonton, Alberta, Canada. ${ }^{3}$ Faculty of Medicine and Dentistry, University of Alberta, Edmonton, Alberta, Canada. ${ }^{4}$ Faculty of Nursing, University of Alberta, Edmonton, Alberta, Canada. ${ }^{5}$ Division of Critical Care Medicine, Clinical Sciences Building, 2-124E, 8440 - 112 Street, Edmonton, Alberta T6G 2B7, Canada.

Received: 29 May 2014 Accepted: 30 October 2014

Published online: 18 November 2014

\section{References}

1. Statistics Canada: Annual demographic estimates: Canada, provinces and territories 2012. Available at: www.statcan.gc.ca/pub/91-215-x/ 91-215-x2012000-eng.pdf.

2. Bettelli G: Preoperative evaluation in geriatric surgery: comorbidity, functional status and pharmacological history. Minerva Anestesiol 2011, 77:637-646.

3. Neragi-Miandoab S, Wayne M, Cioroiu M, Zank LM, Mills C: Preoperative evaluation and a risk assessment in patients undergoing abdominal surgery. Surg Today 2010, 40:108-113.

4. Krane M, Voss B, Hiebinger A, Deutsch MA, Wottke M, Hapfelmeier A, Badiu CC, Bauernschmitt R, Lange R: Twenty years of cardiac surgery in patients aged 80 years and older: risks and benefits. Ann Thorac Surg 2011, 91:506-513.

5. Scott BH, Seifert FC, Grimson R, Glass PS: Octogenarians undergoing coronary artery bypass graft surgery: resource utilization, postoperative mortality, and morbidity. J Cardiothorac Vasc Anesth 2005, 19:583-588.

6. Leontyev S, Walther T, Borger MA, Lehmann S, Funkat AK, Rastan A, Kempfert J, Falk V, Mohr FW: Aortic valve replacement in octogenarians: utility of risk stratification with EuroSCORE. Ann Thorac Surg 2009, 87:1440-1445

7. Nloga J, Hénaine R, Vergnat M, Wautot F, Desebbe O, Robin J, Ninet J, Obadia JF: Mitral valve surgery in octogenarians: should we fight for repair? A survival and quality-of-life assessment. Eur J Cardiothorac Surg 2011, 39:875-880.

8. Mark DB, Nelson CL, Califf RM, Harrell FE Jr, Lee $K L$, Jones RH, Fortin DF, Stack RS, Glower DD, Smith LR: Continuing evolution of therapy for coronary artery disease. Initial results from the era of coronary angioplasty. Circulation 1994, 89:2015-2025.

9. Bagshaw SM, Webb SA, Delaney A, George C, Pilcher D, Hart GK, Bellomo R: Very old patients admitted to intensive care in Australia and New Zealand: a multi-centre cohort analysis. Crit Care 2009, 13:R45.

10. Friedrich I, Simm A, Kotting J, Tholen F, Fischer B, Silber RE: Cardiac surgery in the elderly patient. Dtsch Arztebl Int 2009, 106:416-422.

11. Gelsomino S, Lorusso R, Livi U, Masullo G, Lucà F, Maessen J, Gensini GF: Cost and cost-effectiveness of cardiac surgery in elderly patients. J Thorac Cardiovasc Surg 2011, 142:1062-1073.

12. Pivatto Júnior F, Kalil RA, Costa AR, Pereira EM, Santos EZ, Valle FH, Bender LP, Trombka M, Modkovski TB, Nesralla IA: Morbimortality in octogenarian patients submitted to coronary artery bypass graft surgery. Arq Bras Cardiol 2010, 95:41-46. 
13. Sen B, Niemann B, Roth P, Aser R, Schonburg M, Boning A: Short- and long-term outcomes in octogenarians after coronary artery bypass surgery. Eur J Cardiothorac Surg 2012, 42:e102-e107.

14. Maganti M, Rao V, Brister S, Ivanov J: Decreasing mortality for coronary artery bypass surgery in octogenarians. Can J Cardiol 2009, 25:e32-e35.

15. Di Eusanio M, Fortuna D, Cristell D, Pugliese P, Nicolini F, Pacini D, Gabbieri D, Lamarra M: Contemporary outcomes of conventional aortic valve replacement in 638 octogenarians: insights from an Italian Regional Cardiac Surgery Registry (RERIC). Eur J Cardiothorac Surg 2012, 41:1247-1252. discussion 52-3.

16. Langanay T, Flécher E, Fouquet O, Ruggieri VG, De La Tour B, Félix C, Lelong $B$, Verhoye JP, Corbineau H, Leguerrier A: Aortic valve replacement in the elderly: the real life. Ann Thorac Surg 2012, 93:70-77. discussion 7-8.

17. Filsoufi F, Rahmanian PB, Castillo JG, Chikwe J, Silvay G, Adams DH: Excellent early and late outcomes of aortic valve replacement in people aged 80 and older. J Am Geriatr Soc 2008, 56:255-261.

18. Nagendran J, Norris C, Maitland A, Koshal A, Ross DB: Is mitral valve surgery safe in octogenarians? Eur J Cardiothorac Surg 2005, 28:83-87.

19. Alexander KP, Anstrom KJ, Muhlbaier LH, Grosswald RD, Smith PK, Jones RH, Peterson ED: Outcomes of cardiac surgery in patients > or $=80$ years: results from the National Cardiovascular Network. J Am Coll Cardiol 2000, 35:731-738.

20. Statistics Canada: Life Tables, Canada, Provinces and Territories 2005 to 2007. Available at: http://www.statcan.gc.ca/pub/84-537-x/2013001/tbl-eng.htm.

21. Barnett SD, Halpin LS, Speir AM, Albus RA, Akl BF, Massimiano PS, Burton NA, Collazo LR, Lefrak EA: Postoperative complications among octogenarians after cardiovascular surgery. Ann Thorac Surg 2003, 76:726-731.

22. Lee DH, Buth KJ, Martin BJ, Yip AM, Hirsch GM: Frail patients are at increased risk for mortality and prolonged institutional care after cardiac surgery. Circulation 2010, 121:973-978.

doi:10.1186/s13019-014-0177-6

Cite this article as: Wang et al: Association between older age and outcome after cardiac surgery: a population-based cohort study. Journal of Cardiothoracic Surgery 2014 19:177.

\section{Submit your next manuscript to BioMed Central and take full advantage of:}

- Convenient online submission

- Thorough peer review

- No space constraints or color figure charges

- Immediate publication on acceptance

- Inclusion in PubMed, CAS, Scopus and Google Scholar

- Research which is freely available for redistribution 